\title{
Pengaruh Model Pembelajaran Penemuan Berbasis Mind Mapping terhadap Hasil Belajar Fisika Siswa Kelas VIII SMP Negeri 18 Palu
}

\author{
Nurhaisah Kadir, Marungkil Pasaribu dan Syamsu \\ nurhaisahk@gmail.com \\ Program Studi Pendidikan Fisika FKIP Universitas Tadulako \\ Jl. Soekarno Hatta Km. 9 Kampus Bumi Tadulako Tondo Palu - Sulawesi Tengah
}

\begin{abstract}
Abstrak - Penelitian ini bertujuan untuk melihat ada tidaknya pengaruh model pembelajaran discovery berbasis mind mapping terhadap hasil belajar fisika siswa kelas VIII SMP Negeri 18 Palu. Jenis penelitian yang digunakan yaitu eksperimen kuasi dengan desain "The Non Equivalen Pretest-Posttest Group Design". Sampel dipilih menggunakan teknik purposive sampling. Kelas VIII F sebagai kelas kontrol dan kelas VIII G sebagai kelas eksperimen. Instrumen yang digunakan berupa tes hasil belajar fisika dalam bentuk pilihan ganda yang telah divalidasi melaui validitas ahli dan teknik analisa data. Berdasarkan hasil pengolahan data, untuk kelas eksperimen diperoleh rerata skor tes akhir adalah 9,63 dengan standar deviasi sebesar 2,82. Untuk kelas kontrol diperoleh rerata skor tes akhir 7,32 dengan standar deviasi sebesar 2,36. Hasil pengujian hipotesis diperoleh nilai $t_{\text {hitung }}=$ 2,96 dan $t_{\text {tabel }}=2,02$. Ini berarti bahwa nilai $t_{\text {hitung }}$ berada di luar daerah penerimaan $\mathrm{H}_{0}$. Hasil ini memberi peluang untuk menyatakan terdapat perbedaan hasil belajar fisika antara kelas kontrol dan kelas eksperimen. Dengan demikian dapat disimpulkan terdapat pengaruh model pembelajaran discovery berbasis mind mapping terhadap hasil belajar fisika siswa kelas VIII SMP Negeri 18 Palu.
\end{abstract}

Kata Kunci: Discovery,Mind Mapping, Hasil Belajar Fisika.

\section{PENDAHULUAN}

Pendidikan merupakan landasan utama dalam menciptakan generasi bangsa yang cerdas, bermoral, mampu mengikuti perkembangan teknologi dunia, dan memiliki kecakapan individu sebagai bekal dalam kehidupan bermasyarakat. Kesuksesan dalam pendidikan membawa bangsa menjadi maju dan mampu bersaing secara global. Melalui pendidikan, berbagai disiplin ilmu dibekalkan kepada siswa. Berbicara tentang pendidikan, belum sempurna jika belum berbicara tentang guru. Guru memiliki peran yang sangat penting dalam menentukan kuantitas dan kualitas pengajaran yang dilaksanakannya. Keberhasilan penyelenggara pendidikan banyak ditentukan oleh proses belajar mengajar yang ditangani langsung oleh para guru.

Salah satu metode pembelajaran yang sering digunakan dalam kegiatan belajar mengajar adalah ceramah. Metode ceramah adalah sebuah bentuk interaksi melalui penerangan dan penuturan lisan dari guru kepada peserta didik. Metode akan membuat siswa hanya aktif membuat catatan saja sehingga pembelajaran akan menjadi tidak bermakna. [1].

Pembelajaran akan bermakna ketika suatu kegiatan menghubungkan konsep-konsep untuk mendapatkan atau menghasilkan pemahaman yang utuh sehingga konsep yang dipelajari akan dipahami secara baik dan tidak mudah dilupakan. Dan salah satu model pembelajaran yang mengarah pada siswa untuk mengamati, menanya, mengolah, menyajikan dan mencipta sehingga proses pembelajaran akan melibatkan siswa untuk menemukan sendiri berbagai konsep yang dipelajari adalah discovery. Model pembelajaran ini akan membantu siswa memperbaiki dan meningkatkan proses dan keterampilan kognitif mereka. Pada dasarnya anak memiliki sifat aktif, kontruktif dan mampu merencanakan sesusatu, mampu mencari, menemukan dan menggunakan pengetahuan yang diperolehnya. [2].

Model pembelajaran discovery merupakan salah satu alternatif model pembelajaran yang membimbing siswa untuk menemukan hal-hal baru bagi siswa berupa konsep maupun rumus. Model pembelajaran discovery juga mampu mengaitkan konsep-konsep relevan yang telah dimiliki siswa dan melibatkan proses berpikir siswa sehingga mendorong siswa aktif dalam pembelajaran. Agar model pembelajaran discovery lebih efektif, efisien dan menyenangkan bagi peseta didik maka digunakanlah mind mapping. Mind Mapping atau sering disebut dengan peta pikiran merupakan cara mencatat yang berusaha mengaktifkan otak kanan dan otak kiri bekerja secara seimbang. Mind Mapping dapat membuat catatan yang menarik dan unik, yang dapat membangkitkan keinginan siswa untuk mencatat dan 
membangkitkan rasa ingin kembali melihat dan memperbaiki catatan-catatan yang salah. [3].

Pembelajaran dengan model pembelajaran discovery berbasis mind mappping memungkinkan siswa akan lebih aktif dan tertarik dalam belajar, hal ini dikarenakan mind mapping adalah cara belajar yang menggunakan media mencatat atau cara mencatat yang menyenangkan, efektif, cara mudah memasukkan dan mengeluarkan informasi dalam otak. Serta mengoptimalisasi potensi otak secara keseluruhan dan kesesuaian pembelajaran dengan karakteristik siswa dan materi IPA Fisika. Sehingga, pembelajaran discovery berbasis mind mapping (peta pikiran) dianggap tepat untuk meningkatkan hasil belajar siswa.

\section{METODE PENELITIAN}

Jenis penelitian yang di gunakan adalah eksperimen kuasi yang berupaya mengungkapkan hubungan sebab akibat dengan cara melibatkan kelompok kontrol dan kelompok eksperimen, dengan mempertimbangkan sulitnya mengontrol semua variabel yang mempengaruhi variabel yang sedang diteliti. Penelitian eksperimen kuasi, digunakan karena pada kenyataannya sulit mendapatkan kelompok kontrol yang di gunakan untuk penelitian [4].

Desain penelitiannya adalah 'the nonequivalent pretest - postest design". Desain ini menggunakan kelas-kelas yang sudah ada sebagai kelompoknya, dengan memilih kelaskelas yang diperkirakan sama keadaan/kondisinya, dalam hal ini sama berdasarkan tingkat kecerdasan. Pada penelitian ini digunakan dua kelas yaitu satu kelas yang berfungsi sebagai kelas eksperimen dan satu kelas berfungsi sebagai kelas kontrol. Adapun desain penelitiannya disajikan seperti pada Tabel 1.

TABEL 1 DESAIN PENELITIAN THE NON EKUIVALEN PRETEST-POSTEST

\begin{tabular}{cccc}
$D E S I G N$ & & & \\
\hline Kelompok & Tes awal & Penelitian & Tes akhir \\
\hline Eksperimen $(\mathrm{Xa})$ & $\mathrm{O} 1$ & $\mathrm{X}$ & $\mathrm{O} 2$ \\
Kontrol $(\mathrm{Xb})$ & $\mathrm{O} 1$ & - & $\mathrm{O} 2$ \\
\hline
\end{tabular}

Keterangan:

$X$ : Perlakuan menggunakan model pembelajaran discovery berbasis mind mapping

01 : Tes awal

02 : Tes akhir

Populasi yang digunakan pada penelitian ini adalah seluruh siswa kelas VIII SMP Negeri 18 semester genap pada tahun ajaran 2016/2017 yang tersebar dalam 8 kelas. Kelas VIII $F$ sebagai kelas kontrol dan kelas VIII G sebagai kelas eksperimen.
Pengambilan sampel pada penelitian ini adalah purposive sampling, yaitu teknik penentuan sampel dengan pertimbangan tertentu dari guru mata pelajaran fisika pada kedua kelas di sekolah tersebut. Kedua kelas yang dipilih merupakan kelas yang dianggap homogen secara akademik.

Data yang diperoleh dari penelitian ini selanjutnya diolah dengan menggunakan uji statistik berupa uji normalitas (Chi kuadrat), uji homogenitas (Fisher), dan uji hipotesis (uji-t dua pihak).

\section{HASIL DAN PEMBAHASAN}

\section{A) Hasil Penelitian}

Hasil pengolahan data pre-test dan post-test untuk masing-masing kelas yaitu kelas eksperimen dan kelas kontrol, diperoleh nilai maksimum, nilai minimum, nilai rata-rata dan standar deviasi. seperti pada Tabel 2.

TABEL 2 DESKRIPSI SKOR TES HASIL BELAJAR FISIKA SISWA UNTUK KELAS EKSPERIMEN DAN KELAS KONTROL

\begin{tabular}{lcccc}
\hline \multirow{2}{*}{ Uraian } & \multicolumn{2}{c}{ Pre-test } & \multicolumn{2}{c}{ Post-test } \\
\cline { 2 - 5 } & Eksperimen & Kontrol & Eksperimen & Kontrol \\
\hline Sampel $(\mathrm{n})$ & 23 & 22 & 23 & 22 \\
Skori maks & 14 & 11 & 14 & 12 \\
Skor min & 3 & 3 & 6 & 4 \\
Skor rata & 7,15 & 6,50 & 9,63 & 7,32 \\
Standar dev & 3,11 & 2,45 & 2,82 & 2,36 \\
\hline
\end{tabular}

Uji normalitas data digunakan untuk mengetahui apakah populasi data berdistribusi normal atau tidak. Data yang akan diuji normalitas adalah data hasil Pretest pada kelas eksperimen dan kelas kontrol. Pengujian normalitas data preetest pada penelitian menggunakan uji Chi-kuadrat dengan kriteria penerimaan $X^{2}$ hitung $<X^{2}$ tabel, taraf signifikan $a=$ 0,05 , dan derajat kebebasan $\mathrm{dk}=\mathrm{k}-3$ hasil pengujian normalitas tes awal antara kelas eksperimen maupun kelas kontrol dapat dilihat pada Tabel 3.

TABEL 3 HASIL UJI NORMALITAS TES AWAL KELAS EKSPERIMEN DAN KELAS

\begin{tabular}{ccc}
\multicolumn{2}{c}{ KONTROL } \\
\multirow{2}{*}{ Uraian } & \multicolumn{3}{c}{ Tes Awal } \\
\cline { 2 - 3 } & 23 & 22 \\
Sampel & 4,88 & 2,46 \\
$X^{2}$ hitung & 7,81 & 5,99 \\
$X^{2}$ tabel & \multicolumn{2}{c}{ Normal } \\
Keterangan & \multicolumn{3}{c}{} \\
\hline
\end{tabular}

Dari Tabel 3 terlihat bahwa nilai $\mathrm{X}^{2}$ hitung kelas eksperimen maupun kelas kontrol lebih kecil daripada nilai $X^{2}(1-a)(k-3)$. Artinya, hasil ini menunjukan bahwa data tes awal kelas eksperimen maupun kelas kontrol terdistribusi normal. 
Pengujian data homogenitas ini menggunakan uji-F dengan kriteria jika $F_{\text {hitung }}<F_{\text {tabel }}$ maka data homogen. Hasil uji homogenitas dari kelas eksperimen dan kelas kontrol dapat dilihat pada Tabel 4.

TABEL 4 HASIL UJI HOMOGENITAS TES AWAL

\begin{tabular}{ccc}
\multicolumn{4}{c}{ TABEL 4 HASIL UJI HOMOGENITAS TES AWAL } \\
\hline Uraian & Tes awal & Keterangan \\
\hline F $_{\text {hitung }}$ & 1,61 & Homogen \\
Ftabel & 2,03 & \\
\hline
\end{tabular}

Berdasarkan kriteria, dimana $F_{\text {hitung }}<F_{\text {tabel }}$ maka data tersebut bersifat homogenitas. Berdasarkan Tabel 4 dimana nilai $F_{\text {hitung }}<F_{\text {tabel. }}$. Hal ini menunjukkan bahwa data tersebut memiliki varians yang sama (homogen).

Setelah terpenuhinya uji normalitas dan homogenitas, maka dilakukan uji-t dua pihak. Uji $\mathrm{t}$ tersebut diperoleh berdasarkan data tes awal dapat dilihat pada Tabel 5.

TABEL 5 UJI BEDA RATA-RATA (DUA PIHAK) TES AWAL KELAS EKSPERIMEN DAN KELAS KONTROL

\begin{tabular}{cccccc}
\hline No & Kelas & $\begin{array}{c}\text { Nilai rata- } \\
\text { rata } \bar{X}\end{array}$ & $\mathrm{t}_{\text {hitung }}$ & $\mathrm{t}$ table & $\begin{array}{c}\text { Keputus } \\
\text { an }\end{array}$ \\
\hline 1 & Kelas Eks & 7,15 & 0,78 & 2,02 & $\begin{array}{c}\mathrm{H}_{0} \\
\text { diterima }\end{array}$ \\
2 & Kelas Kont & 6,50 & 0,50 & & \\
\hline
\end{tabular}

Berdasarkan data Tabel 5 diketahui thitung $\leq$ tabel atau $0,78 \leq 2,02$. Hal tersebut berarti, nilai thitung berada pada daerah penerimaan $\mathrm{H}_{0}$. Dengan demikian $\mathrm{H}_{0}$ diterima dan $\mathrm{H}_{1}$ ditolak, dan dapat disimpulkan bahwa tidak ada perbedaan hasil belajar fisika antara kelompok siswa dengan pembelajaran discovery berbasis mind mapping dengan kelompok siswa yang menggunakan model pembelajaran discovery. Berdasarkan hasil postest yang diberikan pada kelas eksperimen dan kelas kontrol maka diperoleh hasil untuk kelas eksperimen nilai minimum 6 dan nilai maksimum 14. Nilai rata-rata pada kelas eksperimen sebesar 9,63. Pada kelas kontrol diperoleh nilai minimum 4 dan nilai maksimum 12. Untuk nilai rata-rata pada kelas kontrol 7,32. Adapun data tersebut disajikan pada Tabel 6 .

TABEL 6 SKOR TES AKHIR HASIL BELAJAR FISIKA

\begin{tabular}{ccc}
\hline Keterangan & $\begin{array}{c}\text { Kelas Kontrol } \\
\left(\mathrm{X}_{\mathrm{c}}\right)\end{array}$ & $\begin{array}{c}\text { Kelas Eksperimen } \\
\left(\mathrm{X}_{\mathrm{b}}\right)\end{array}$ \\
\hline Skor minimum & 4 & 6 \\
Skor maksimum & 12 & 14 \\
Jumlah siswa & 22 & 23 \\
Skor rata - rata & 7,32 & 9,63 \\
Standar deviasi & 2,36 & 2,82 \\
\hline
\end{tabular}

Setelah terpenuhinya uji normalitas dan homogenitas, maka dilakukan uji-t dua pihak. Uji t tersebut diperoleh berdasarkan data tes akhir. Hasil dapat dilihat pada Tabel 7.
TABEL 7 UJI HIPOTESIS POSTEST

\begin{tabular}{|c|c|c|c|c|c|}
\hline No & Kelas & $\bar{X}$ & $t_{\text {hitung }}$ & $\begin{array}{c}t_{\text {tabel }} \\
(\alpha= \\
0,05)\end{array}$ & Keputusan \\
\hline $\begin{array}{l}1 \\
2\end{array}$ & $\begin{array}{l}\text { Eksperimen } \\
\text { Kontrol }\end{array}$ & $\begin{array}{l}9,63 \\
7,32\end{array}$ & 2,96 & 2,02 & $\mathrm{H}_{0}$ ditolak \\
\hline
\end{tabular}

Berdasarkan Tabel 7 thitung $>t_{\text {tabel }}$ atau 2,96 > 2,02. Hal ini berarti, nilai thitung berada diluar daerah penerimaan $\mathrm{H}_{0}$. Dengan demikian $\mathrm{H}_{0}$ ditolak dan $\mathrm{H}_{1}$ diterima. Yang berarti terdapat perbedaan hasil belajar fisika antara kelompok siswa yang mengikuti pembelajaran discovery berbasis mind mapping dengan kelompok siswa yang mengikuti pembelajaran discovery. Sehingga dapat disimpulkan bahwa terdapat pengaruh model pembealajaran discovery berbasis mind mapping terhadap hasil belajar fisika siswa kelas VIII SMP Negeri 18 Palu.

\section{B) Pembahasan}

Berdasarkan data hasil penelitian, dilakukan uji normalitas, homogenitas dan hipotesis untuk mengetahui keadaan awal siswa. Dari hasil uji normalitas, homogenitas dan hipotesis diperoleh data bahwa keadaan awal siswa yang dijadikan sampel adalah terdistribusi normal, homogen dan tidak ada perbedaan dari segi pengetahuan sehingga dapat digunakan untuk penelitian.

Penelitian ini, hasil tes akhir menunjukan perolehan skor rata-rata hasil belajar siswa pada kelas eksperimen dan kelas kontrol berbeda. Skor rata-rata kelas eksperimen adalah 9,63 dan kelas kontrol adalah 7,32. Hasil belajar siswa yang diberi model pembelajaran discovery berbasis mind mapping lebih tinggi dari siswa yang diberi model pembelajaran discovery. Berdasarkan hasil uji-t diperoleh bahwa setelah dilakukan model pembelajaran discovery berbasis mind mapping terdapat pengaruh hasil belajar fisika. Hal ini menunjukan bahwa model pembelajaran discovery berbasis mind mapping akan mempengaruhi hasil belajar fisika siswa dibandingkan dengan model pembelajaran discovery, walaupun peningkatan hasil belajarnya rendah. Dikarenakan, pada kelas yang mengikuti model pembelajaran discovery berbais mind mapping memberikan kesempatan kepada siswa untuk bekerja sama menuangkan ide kreatif mereka kedalam bentuk gambar-gambar.

Model pembelajaran discovery terdiri dari 6 tahapan yang kemudian dikombinasikan dengan mind mapping yang diajarkan pada kelas eksperimen dan pada kelas kontrol hanya menggunakan model pembelajaran discovery saja. Dikedua kelas yang dijadikan sampel peneliti sama-sama menggunakan model pembelajaran discovery yang memenuhi 6 tahap tersebut yang kemudian perbedaannya hanya 
p-ISSN 2338-3240, e-ISSN 2580-5924

terletak pada proses dari tahapan keempat dari model pembelajaran discovery itu sendiri.

Tahap pertama yaitu tahapan stimulation. Guru menyajikan sebuah gambar mengenai materi tekanan zat padat kepada siswa untuk melihat permasalahan utama yang terdapat pada gambar sehingga timbulnya motivasi sekaligus rasa ingin tahu siswa.

Tahap kedua yaitu problem statement. Guru menanyakan berbagai pertanyaan berdasarkan gambar mengenai materi tekanan zat padat yang diamati oleh siswa. Hal inilah yang akan digunakan sebagai pengetahuan awal siswa.

Tahap ketiga yaitu data collecting. Pada tahap ini siswa diberikan kesempatan untuk mencari jawaban ataupun informasi lainnya untuk menjawab pertanyaan-pertanyaan yang ada dengan menggunakan buku pegangan atau referansi lainnya.

Tahap keempat, data processing yaitu kelompoknya masing masing melakukan suatu eksperimen sederhana. Pada tahap ini, untuk kelas eksperimen yaitu tiap kelompok melakukan eksperimen sederhana mengenai materi tekanan zat padat dan setelah melakukan eksperimen, tiap kelompok tersebut akan mendapatkan tugas membuat mind mapping. Siswa dilatih untuk mandiri dalam mengembangkan materi pokok mengenai tekanan zat padat yang telah diajarkan oleh guru sebelum mereka membuat mind mapping. Selain itu, melalui model pembelajaran discovery berbasis mind mapping dapat meningkatkan kemampuan penemuan siswa seerta merubah kondisi belajar dari pasif menjadi lebih aktif, tertarik dalam belajar dan berani dalam berkreasi. Sehingga dengan mind mapping yang berupa tulisan dan gambar berwarna warni yang telah mereka buat sendiri akan memudahkan mereka dalam mengingat materi tersebut, dibandingkan dengan bentuk catatan biasa. Tulisan, gambar dan simbol yang mereka buat diberi warna yang berbeda setiap cabangnya. Untuk materi tekanan pada zat padat misalnya, setiap kelompok bisa membuat empat cabang atau lebih. Dengan setiap cabang yang memiliki warna yang berbeda. Misalnya untuk cabang pertama yaitu tekanan zat padat dengan warna merah, cabang kedua faktor-faktor tekanan zat padat dengan warna hijau, cabang ketiga hukum contoh dalam kehidupan sehar hari beserta gambarnya dengan warna kuning dan rumus dan keterangan dengan warna biru. Jumlah cabang yang akan dibuat tiap kelompok tidak dibatasi jumlahnya, sesuai dengan kreatif mereka masing masing. Sedangkan untuk kelas kontrol pada tahap ini, melakukan eksperimen sederhana. Tiap kelompok melakukan eksperimen sederhana seperti tekanan zat padat dan setelah melakukan eksperimen tiap kelompok akan menulis data hasil eksperimen dan mendiskusikan pertanyaan - pertanyaan yang ada pada LKS yang telah diberikan.

Tahap kelima, untuk kelas eksperimen dan kelas kontrol, verification yaitu guru membimbing siswa untuk mengecek kembali kebenaran hasil eksperimen mengenai materi tekanan zat padat yang telah dilakukan melalui buku pegangan atau sumber belajar lainnya.

Tahap terakhir, generalization yaitu guru meminta satu kelompok untuk mempresentasikan hasil kerja kelompoknya dan kemudian bersama - sama dengan siswa untuk membuat kesimpulan akhir dari materi yang telah diajarkan.

Hal yang tampak dalam penelitian ini, melalui penggunaan metode mind mapping siswa akan semakin terlatih untuk berkerja sama, lebih kreatif dalam berfikir, karena didorong oleh rasa kompetisi diantara kelompok untuk saling berusaha menjadi yang terbaik dengan suasana belajar yang menyenangkan dan tidak tegang. Selain itu, gambar yang dihasilkan oleh setiap kelompok terdiri dari beraneka ragam warna tergantung kesepakatan dari anggota kelompok masing masing dengan disetiap cabangnya terdiri dari satu warna untuk suata penjelasan tertentu. Hal inilah yang membuat pembelajaran menjadi lebih menarik sehingga siswa tidak merasa jenuh saat proses belajar mengajar berlangsung.

Berdasarkan hasil penelitian sebelumnya yang dilakukan oleh Susanti (2015) dengan judul pengaruh penerapan LKPD berbasis discovery learning berbantuan mind map terhadap kompetensi IPA peserta didik kelas VII SMPN 6 Bukittinggi yang menyatakan bahwa penerapan LKPD berbasis discovery learning berbantuan mind mapping memberikan pengaruh yang berarti terhadap kompetensi IPA siswa. Kompetensi IPA yang ditinjau berdasarkan dengan hasil belajar dan keterampilan. Dengan melakukan model pembelajaran discovery yang berarti penemuan yang artinya siswa menggunakan proses mentalnya dalam usaha menemukan sendiri konsep-konsep atau prinsipprinsip yang dipelajarinya. Model pembelajaran discovery dapat meningkatkan kemampuan penemuan peserta didik serta merubah kondisi belajar yang pasif menjadi aktif dan kreatif. Kemudian dengan menggunakan model pmbelajaran discovery berbasis mind mapping penemuan menjadi lebih efektif, efisien dan menyenangkan bagi siswa. [5].

Kedua pembelajaran ini masih mempunyai kekurangan dalam pelaksanaannya dilapangan. Pada kelas eksperimen yang menggunakan pembelajaran discovery berbasis mind mapping, konsep yang diperoleh pada siswa yang tidak memiliki buku panduan hanya sebatas konsep- 
konsep penting yang telah disampaikan oleh guru dan mind mapping yang telah mereka buat. Karena guru lebih berfokus dalam membimbing siswa untuk memecahkan masalah dalam membuat mind mapping. Sedangkan pada pembelajaran discovery yang diterapkan dikelas kontrol yaitu saat tahap data processing ada kelompok siswa yang cenderung hanya sebagian yang mengerjakan dalam suatu kelompok, hal ini disebabkan karena mereka merasa jenuh dan mereka anggap hal yang tidak menyenangkan.

Di luar permasalahan yang menyangkut kekurangan pembelajaran yang digunakan, faktor lain yang harus menjadi perhatian adalah kondisi siswa yang beragam sehingga diluar jangkauan peniliti. Namun dengan kelebihan dan kekurangan yang dimiliki pembelajaran discovery berbasis mind mapping ini, peniliti tetap merekomendasikan pembelajaran ini untuk diterapkan dalam proses belajar mengajar di sekolah karena ketika pembelajaran ini diterapkan dengan baik dan benar maka hasil yang diharapkan akan lebih maksimal.

\section{KESIMPULAN DAN SARAN}

\section{A) Kesimpulan}

Berdasarkan hasil pengolahan data, untuk kelas eksperimen diperoleh rerata skor tes akhir adalah 9,63 dengan standar deviasi sebesar 2,82 . Untuk kelas kontrol diperoleh rerata skor tes akhir 7,32 dengan standar deviasi sebesar 2,36 . Hasil pengujian hipotesis diperoleh nilai $t_{\text {thitung }}=2,96$ dan tabel $=2,02$. Ini berarti bahwa nilai thitung berada di luar daerah penerimaan $\mathrm{H}_{0}$. Hasil ini memberi peluang untuk menyatakan terdapat perbedaan hasil belajar fisika antara kelas kontrol dan kelas eksperimen. Dengan demikian dapat disimpulkan terdapat pengaruh model pembelajaran discovery berbasis mind mapping terhadap hasil belajar fisika siswa kelas VIII SMP Negeri 18 Palu.

B) Saran - Saran

a) Untuk peneliti selanjutnya diharapkan lebih mengoptimalkan pengelolaan kelas khususnya pada saat pembelajaran berlangsung agar tidak terjadi kegaduhan kegaduhan di dalam kelas. .

b) Sebelum penelitian berlangsung peneliti harus terlebih dahulu memperkenalkan siswa tentang mind mapping serta mengajari siswa dalam pembuatan mind mapping yang benar agar proses pembelajaran dapat berjalan dengan baik dan siswa trampil dalam membuatnya.

\section{DAFTAR PUSTAKA}

[1] Pramukti, S.H. (2013). Komparasi Pengaruh Penggunaan Metode Ceramah Dan Team Game Tournament Kelas IPS SMA Negeri 1 Teras Boyolali. Jurnal Pendidikan Sosiologi, Volume 10, Nomor 1, hlm $1-15$

[2] Mutmaina. (2009). Pendekatan Pembelajaran (Discovery Learning) untuk Meningkatkan Keterampilan Diskusi Siswa kelas VII SMP Negeri 4 Palu. Skripsi Program Studi Pendidikan Fisika Fkip Untad : tidak diterbitkan

[3] Buzan, T. (2009). Buku Pintar Mind Map. Jakarta: PT. Gramedia Pustaka Utama.

[4] Sugiyono. 2010. Metode Penelitian Pendidikan Pendekatan Kuantitatif, Kualitatif, dan R \& D. Bandung : Alfabeta

[5] Susanti dan Wulan, R. (2015). Pengaruh Penerapan Lkpd Berbasis Discovery Learning Berbantuan Mind Map Terhadap Kompetensi Ipa Peserta Didik Kelas Vii Smpn 6 Bukittinggi. Pillar Of Physics Education, Vol. 5. April 2015, 145-152. 